\title{
Medical Students Knowledge and Perception Regarding Complementary and Alternative Medicine
}

Firdous Jahan ${ }^{1^{*}}$, Mustafa Manhal Al-Ward ${ }^{1}$, Muhammad A Siddiqui ${ }^{2}$ and Maryam Abdul-Jabar Al-Khouri ${ }^{1}$

${ }^{1}$ Department Family Medicine, Oman Medical College, Oman

${ }^{2}$ School of Health Sciences, Queen Margaret University, Edinburgh, UK

"Corresponding author: Firdous Jahan, Associate professor, Head of the Department, Family Medicine(FAMCO), Oman Medical College, Sohar-391, Al Tareef, SoharSultanate of Oman, Oman, Tel: +968-26844004; E-mail: firdous@omc.edu.om

Rec date: Jun 14, 2015; Acc date: Aug 14, 2015; Pub date: Aug 17, 2015

Copyright: ( 2015 Jahan F, et al. This is an open-access article distributed under the terms of the Creative Commons Attribution License, which permits unrestricted use, distribution, and reproduction in any medium, provided the original author and source are credited.

\begin{abstract}
Objective

The purpose of the study was to identify knowledge and perception of medical students regarding complementary and alternative medicine therapy (CAM).

\section{Background}

Complementary and alternative medicine (CAM) is growing field in medicine, which can be a useful resource to improve the quality of life. Medical students should be aware of these modalities available freely for the patient as over the counter medicine.

Methods

A cross- sectional survey based study carried out on 6th and 7th year medical students (clinical years). Data was collected on self-administered questionnaire in which core elements were divided-Knowledge and Perception about CAM and Knowledge regarding Herbs used as Pain Killer. Statistical analysis was performed using SPSS (IBM SPSS Statistics 20.0). Data were expressed in frequencies, mean and percentages.

\section{Results}

Less than a half $(44.9 \%)$ of the participants were 7 th year and $(55.1 \%)$ were 6 th year students. Majority of the students $(80.5 \%)$ were Omani 53 (45\%) of study participants were below 25 years in age and $101(85.6 \%)$ were female. No difference was observed between 6th and 7th year students ( $\mathrm{p}-0.516,95 \%$ CI-1.74-3.31), significant difference ( $\mathrm{p}-0.009,95 \%$ CI 1.25-8.44). Significant difference was observed (p-0.009, 95\% CI-7.45-1.08) between Omani and non-Omani participants. Students possess adequate knowledge about CAM and positive approach in clinical practice but overall they have poor knowledge about herb as pain killer.

\section{Conclusion}

Students in clinical years have positive approach towards CAM and their knowledge is adequate in general but they have poor knowledge regarding herbs used as pain killer.
\end{abstract}

Keywords: Complementary and alternative medicine; Medical students; Knowledge and perception

\section{Introduction}

Complementary and alternative medicine (CAM) is growing very fast and the use of CAM in health care is rapidly evolving [1]. CAM has been defined by the National Center for Complementary and Alternative Medicine as a group of diverse medical and health care systems, practices, and products that are not presently considered to be part of conventional medicine [2]. They may be grouped into categories such as natural products, mind-body, and body-based practices. CAM is a broad domain of healing resource to improve the quality of life and can be a valuable addition to the chronic pain management plan. CAM is mainly used as self-medication patients' own beliefs, and the wish for more control over one's own health [3-4]. Which could be herbs, vitamins, minerals, or other natural products, some of them have been studied for pain control. Some are called mind-body medicines [5-6]. People use CAM, especially herb as selfmedication to reduce symptoms and to improve well-being thinking that it has no side effects. Herbal Medicine is the use of preparations, which contain exclusively plant material [7].

Medical student's knowledge is limited as CAM is not formally included in undergraduate curriculum [8,9]. Although alternate medicine therapy in family Medicine rotation each disease 
management covers but still it is not taught as conventional medications. Family medicine is an essential component of the primary care infrastructure of the Oman health care delivery system. This primary care specialty provides first contact, ongoing, and preventive care to all patients. Both the clinical courses (year 6 and 7 ) run as a spiral with consolidating and sharpening the knowledge and skills acquired in year 6 with some more practical approach in year 7. Oman Medical College is aware of the importance of CAM and has taken initiatives to enhance its awareness among medical student to develop and organize strategies with a view to formulating education programs. In their pre-clinical year students learn basics of CAM and their application in clinical practice followed by assessment in that area. CAM is now included in clinical years' curriculum to teach and train the students to be an effective doctor and have competence to provide high standards of care to meet the health need of people of Oman and the region.

To strengthen and make it more effective in terms of teaching and experiential learning of CAM, few steps is already being taken. Thus, a process of needs assessment, identifying gaps in knowledge, consultations with the curricula reformers and strategic planning is thought to be effective catalysts for curricular change [9]. This study was designed to assess the knowledge and perception of medical students regarding complementary and alternative medicine.

\section{Method}

The survey of 118 medical students carried out at Oman Medical College. The questionnaire designed was divided in to 3 sections. The first section consists of demographic details of students (age, gender and year of education) and second section contains questions regarding knowledge and perception about CAM and third knowledge regarding herbs used as pain killer. All questions had five responses (strongly agree, agree, neutral, disagree, and strongly disagree).

The questionnaire was prepared and approved with ethical review committee of Oman Medical College. All students in clinical years were invited to participate. Participants were enrolled after taking written informed consent. The principal investigator (PI) ensured uniformity and two trained research assistants assisted PI in data collection.

Statistical analysis was performed using SPSS (IBM SPSS Statistics 20.0). Data were expressed in frequencies, mean and percentages.
Mean scale scores for the year of class, gender, age and citizenship were evaluated for significance difference using the paired t-test.

\section{Results}

The survey achieved a 76\% response rate. Approximately 53 (45\%) of study participants were below 25 years in age and 101 (85.6\%) were female. Less than a half (44.9\%) was 7 th year. Majority of the students $95(80.5 \%)$ were Omani citizens (Table 1$)$.

\begin{tabular}{|l|l|l|}
\hline \multicolumn{2}{|l|}{ Frequency=n } & Percent $\%$ \\
\hline Age & 65 & 55.1 \\
\hline$>25$ & 53 & 44.9 \\
\hline Gender & \multicolumn{2}{|l|}{} \\
\hline Male & 17 & 14.4 \\
\hline Female & 101 & 85.6 \\
\hline Study Year & \multicolumn{2}{|l|}{} \\
\hline 6th Year & 65 & 55.1 \\
\hline 7 th Year & 53 & 44.9 \\
\hline Nationality & \multicolumn{2}{|l|}{} \\
\hline Omani & 95 & 80.5 \\
\hline Non Omani & 23 & 19.5 \\
\hline
\end{tabular}

Table 1: Demographics.

No difference was observed between 6th and 7th year students $(\mathrm{p}=0.516,95 \%$ CI-1.74-3.31), while significant difference $(\mathrm{p}=0.009$, 95\% CI 1.25-8.44) was found between male and female response. Similarly no difference between age $>25$ and $<25$ years old $(\mathrm{p}=0.585$, $95 \%$ CI $-3.33-1.89)$ and significant difference was observed $(\mathrm{p}=0.009$, 95\% CI -7.45-1.08) between Omani and non-Omani participant's. Table 2 shows participants responses regarding knowledge and perception about CAM.

\begin{tabular}{|l|l|l|l|l|l|l|}
\hline & Strongly Agree & Agree & Neutral & Disagree & $\begin{array}{l}\text { Strongly } \\
\text { Disagree }\end{array}$ & Don't Know \\
\hline Herbs are safe and cost effective & $1(0.8)$ & $28(23.7)$ & $57(48.3)$ & $29(24.6)$ & $3(2.5)$ & 0.0 \\
\hline $\begin{array}{l}\text { Homeopathy is a form of alternative medicine in } \\
\text { which practitioners use highly diluted preparations }\end{array}$ & $5(4.2)$ & $19(16.1)$ & $81(68.6)$ & $10(8.5)$ & $3(2.5)$ & 0.0 \\
\hline $\begin{array}{l}\text { The use of CAM should be asked about during a } \\
\text { regular history taking }\end{array}$ & $48(40.7)$ & $52(44.1)$ & $15(12.7)$ & $2(1.7)$ & $1(0.8)$ & 0.0 \\
\hline $\begin{array}{l}\text { A patient uses CAM in conjunction with conventional } \\
\text { medicine should be encouraged }\end{array}$ & $1(0.8)$ & $25(21.2)$ & $47(39.8)$ & $36(30.5)$ & $9(7.6)$ & 0.0 \\
\hline $\begin{array}{l}\text { It is important to have CAM practices available to } \\
\text { patients }\end{array}$ & $7(5.9)$ & $39(33.1)$ & $52(44.1)$ & $20(16.9)$ & 0.0 & 0.0 \\
\hline $\begin{array}{l}\text { Patients should inform/consult their doctors about } \\
\text { their use of CAM }\end{array}$ & $63(53.4)$ & $42(35.6)$ & $11(9.3)$ & $1(0.8)$ & $1(0.8)$ & 0.0 \\
\hline
\end{tabular}


Citation: Jahan F, Al-Ward MM, Siddiqui MA, Al-Khouri MAJ (2015) Medical Students Knowledge and Perception Regarding Complementary and Alternative Medicine. J Health Edu Res Dev 3: 135. doi:10.4172/2380-5439.1000135

Page 3 of 5

\begin{tabular}{|l|l|l|l|l|l|l|}
\hline $\begin{array}{l}\text { My spiritual/religious beliefs influence my attitudes } \\
\text { toward CAM }\end{array}$ & $9(7.6)$ & $52(44.1)$ & $36(30.5)$ & $14(11.9)$ & $7(5.9)$ & 0.0 \\
\hline Acupuncture can be used to relieve pain. & $13(11)$ & $43(36.4)$ & $55(46.6)$ & $7(5.9)$ & 0.0 \\
\hline $\begin{array}{l}\text { Chiropractic specializes in spinal manipulation and is } \\
\text { used to treat lower back pain. }\end{array}$ & $7(5.9)$ & $21(17.8)$ & $84(71.2)$ & $6(5.1)$ & 0.0 & 0.0 \\
\hline $\begin{array}{l}\text { CAM includes ideas and methods from which } \\
\text { conventional medicine can benefit }\end{array}$ & $8(6.8)$ & $66(55.9)$ & $30(25.4)$ & $14(11.9)$ & 0.0 & 0.0 \\
\hline $\begin{array}{l}\text { CAM therapies not tested in a scientific manner } \\
\text { should be discouraged }\end{array}$ & $38(32.2)$ & $41(34.7)$ & $29(24.6)$ & $8(6.8)$ & $2(1.7)$ & 0.0 \\
\hline $\begin{array}{l}\text { Clinical care should integrate the best of } \\
\text { conventional and CAM practices }\end{array}$ & $20(16.9)$ & $42(35.6)$ & $48(40.7)$ & $7(5.9)$ & $1(0.8)$ \\
\hline $\begin{array}{l}\text { Health care professionals should be able to advise } \\
\text { their patients about commonly used CAM methods. }\end{array}$ & $20(16.9)$ & $58(49.2)$ & $25(21.2)$ & $15(12.7)$ & 0.0 \\
\hline $\begin{array}{l}\text { A formal training or mandatory CAM course should } \\
\text { be included in medical undergraduate curriculum }\end{array}$ & $20(16.9)$ & $38(32.2)$ & $38(32.2)$ & $18(15.3)$ & $4(3.4)$ & 0.0 \\
\hline Hijama is a popular method used in Oman & $37(31.4)$ & $50(42.4)$ & $22(18.6)$ & $8(6.8)$ & $1(0.8)$ \\
\hline $\begin{array}{l}\text { Relaxation techniques increase wellbeing and thus } \\
\text { may contribute to controlling pain }\end{array}$ & $31(26.3)$ & $64(54.2)$ & $19(16.1)$ & $4(3.4)$ & 0.0 \\
\hline $\begin{array}{l}\text { Reflexology refers to massage therapy that is } \\
\text { focused mainly on the feet }\end{array}$ & $12(10.2)$ & $17(14.4)$ & $81(68.6)$ & $7(5.9)$ & 0.0 \\
\hline $\begin{array}{l}\text { Reiki and aroma therapies using smell to create an } \\
\text { environment that is more soothing and relaxing }\end{array}$ & $11(9.3)$ & $33(28)$ & $64(54.2)$ & $9(7.6)$ & $1(0.8)$ \\
\hline
\end{tabular}

Table 2: Knowledge and Perception about CAM-n (\%).

Table 3 shows participants responses regarding knowledge about herbs used as pain killer. No significant difference ( $\mathrm{p}=0.636,95 \%$ CI-7.82-4.79) was found between 6th and 7th year students response, difference between male and female response ( $p=0.625,95 \%$ CI-6.72-11.15), difference between age $>25$ and $<25$ years old
( $\mathrm{p}=0.787,95 \%$ CI $-7.17-5.45)$ and no significant difference was observed ( $\mathrm{p}=0.92,95 \%$ CI-8.31-7.55) between Omani and non-Omani participants response regarding knowledge about herbs used as pain killer.

\begin{tabular}{|l|l|l|l|l|l|l|}
\hline & Strongly Agree & Agree & Neutral & Disagree & $\begin{array}{l}\text { Strongly } \\
\text { Disagree }\end{array}$ & Don't Know \\
\hline Capsaicin relieves arthritis pain(T) & $16(13.6)$ & $47(39.8)$ & 0 & $6(5.1)$ & $1(0.8)$ & $48(40.7)$ \\
\hline Capsaicin cannot be used topically(F) & $3(2.5)$ & $16(13.6)$ & $2(1.7)$ & $37(31.4)$ & $16(13.6)$ & $44(37.3)$ \\
\hline Devil claw is a root used as analgesic(T) & 0 & $12(10.2)$ & 0 & $6(5.1)$ & $6(5.1)$ & $94(79.7)$ \\
\hline Ginger cannot be used as analgesic(F) & $1(0.8)$ & $19(16.1)$ & 0 & $19(16.1)$ & $4(3.4)$ & $75(63.6)$ \\
\hline Krill oil has anti acid property(F) & $2(1.7)$ & $7(5.9)$ & 0 & $6(5.1)$ & $2(1.7)$ & $101(85.6)$ \\
\hline $\begin{array}{l}\text { White willow bark has Aspirin like } \\
\text { property(T) }\end{array}$ & $4(3.4)$ & $21(17.8)$ & 0 & $3(2.5)$ & 0 & $90(76.3)$ \\
\hline $\begin{array}{l}\text { Baswellia has an anti-inflammatory } \\
\text { property(T) }\end{array}$ & $1(0.8)$ & $8(6.8)$ & $1(0.8)$ & $2(1.7)$ & 0 & $106(89.8)$ \\
\hline Curcumin found in turmeric(T) & $9(7.6)$ & $15(12.7)$ & 0 & $5(4.2)$ & $6(5.1)$ & $1(0.8)$ \\
\hline $\begin{array}{l}\text { Bromelain is an extract from pine } \\
\text { apple(T) }\end{array}$ & $2(1.7)$ & $7(5.9)$ & 0 & $5(4.2)$ & $1(0.8)$ & $88(74.6)$ \\
\hline Ginger has Omega 3 fatty acid(F) & $2(1.7)$ & $10(8.5)$ & $17(14.4)$ & $5(4.2)$ & $84(71.2)$ \\
\hline
\end{tabular}


Page 4 of 5

\begin{tabular}{|c|c|c|c|c|c|c|}
\hline $\begin{array}{l}\text { Burdock Root increases blood } \\
\text { pressure }(F)\end{array}$ & $1(0.8)$ & $5(4.2)$ & 0 & $9(7.6)$ & $1(0.8)$ & $102(86.4)$ \\
\hline Nettles good for low back pain( $T$ ) & $1(0.8)$ & $4(3.4)$ & 0 & $5(4.2)$ & $3(2.5)$ & 105(89) \\
\hline Licorice increases blood pressure(T) & 0 & $5(4.2)$ & 0 & $9(7.6)$ & $8(6.8)$ & $96(81.4)$ \\
\hline Skull cap is a Chinese herb(T) & $1(0.8)$ & $13(11)$ & 0 & $3(2.5)$ & $3(2.5)$ & 98(83.1) \\
\hline Alovera juice is not good for acidity $(F)$ & 0 & $7(5.9)$ & $1(0.8)$ & $10(8.5)$ & $1(0.8)$ & 99(83.9) \\
\hline $\begin{array}{l}\text { St. Johns' worth effective in arthritis } \\
\text { pain(T) }\end{array}$ & $2(1.7)$ & $23(19.5)$ & 0 & $15(12.7)$ & $1(0.8)$ & $77(65.3)$ \\
\hline Valerian root acts as tranquilizer( $(T)$ & 0 & $11(9.3)$ & 0 & $2(1.7)$ & $1(0.8)$ & 104(88.1) \\
\hline Fever few is used in migraine $(T)$ & $3(2.5)$ & $7(5.9)$ & 0 & $6(5.1)$ & $2(1.7)$ & 100(84.7) \\
\hline Eucommia found in Garlic(F) & 0 & $6(5.1)$ & 0 & $4(3.4)$ & $1(0.8)$ & $107(90.7)$ \\
\hline $\begin{array}{l}\text { Solanum Incanum used to treat joint } \\
\text { pain }(F)\end{array}$ & 0 & $8(6.8)$ & 0 & $3(2.5)$ & $1(0.8)$ & $106(89.8)$ \\
\hline $\begin{array}{l}\text { Juniper tree leaves soaked in oil used to } \\
\text { treat earache }(F)\end{array}$ & 0 & $5(4.2)$ & 0 & $4(3.4)$ & $2(1.7)$ & $107(90.7)$ \\
\hline
\end{tabular}

Table 3: Knowledge regarding Herbs used as Pain Killer-n (\%).

\section{Discussion}

The use of herbal medicine is very common in the Arab world including Oman and their consumption is increasing at a rapid pace worldwide due to the wide spread belief that these preparations are natural and therefore, safe. This trend is also observed among the general practitioners who are now more interested and inclined towards the use of herbal drugs for the treatment of some common ailments [10]. In Oman, herbal remedies are considered as over the counter (OTC) drugs and thus are easily available through pharmacies. This is reported in literature that medical students and general practitioner both have an opinion that CAM should be included in the curriculum [11].

Our survey based study of medical student's knowledge and perception regarding CAM shows appreciable knowledge and perception (Table 2). Literature also support same evidence and students had positive attitude regarding CAM and its importance to help conventional medicine. This can benefit in future medical practice evidence-based principles have been utilized to effectively teach medical students about [12].

The highest area of agreement in this study was when the participants admitted that the use of CAM should be asked about during a regular history taking, patients should inform/consult their doctors about their use of CAM. Literature reports about appreciable CAM knowledge among medical student and recommended curricular review in medical education [13]. Majority of students in this study agreed that relaxation techniques increase wellbeing and thus may contribute to controlling pain and Hijama is a popular method used in Oman. Participants exhibited appreciable knowledge, interest and attitudes toward CAM. This may suggest that they are not well equipped with knowledge of the efficacy and safety of CAM, and hence are afraid to advise and encourage their patients who suggest the use of CAM. Nevertheless, most students agree that patients should inform doctors about CAM use and that it should be inquired about during history taking.
This is in accordance with earlier literature, since these are the sources which increase one's general knowledge. A previous study reported that nursing students have more positive attitude than medical students. The results showed that student's attitudes are in line with their interests and limited knowledge [14].

Nearly one-third of participants agreed that CAM therapies not tested in a scientific manner should be discouraged and clinical care should integrate the best of conventional and CAM practices. Health care professionals should be able to advise their patients about commonly used CAM methods. Half of them stated that a formal training or mandatory CAM course should be included in medical undergraduate curriculum. This has been reported in literature Studies have shown that medical students would like more instruction about alternative medical therapies before they can provide advice to patients. Medical schools in the western countries are increasingly offering courses addressing alternative medicine in the curriculum [15].

In this study, student's knowledge regarding CAM and herbs as pain killer was not adequate although they exhibited positive attitude towards it. Most participants admitted to be unsure in response to most questions raised. The study has shown that students at different level have different level of knowledge (Table 3). There is a need for integrative curriculum $[16,17]$. Both lectures and direct shadowing appear to be the favorable methods for students. In one of the U.S. institutions, a 3-week elective CAM rotation that integrated rotation and lectures has improved student's positive attitudes and their knowledge [18].

This study agreed with previous studies which revealed that students though possessed inadequate knowledge about CAM most of them believed that it should be used in conjunction with conventional medicine and that, if given adequate training, they would incorporate it in their future medical practice, also will help them make relevant changes in the medical curriculum $[19,20]$. Study participants seems very enthusiastic about CAM, however their knowledge is not 
appropriate regarding the use. CAM learning method is also assessed in publish articles [21]. Literature reports medical student's attitude and knowledge similar to the observation of this study [22].

Another study published from Oman showed the respondent's community pharmacists have a belief on the effectiveness and safety of herbal products reflecting a positive attitude towards dispensing herbal medicines but their knowledge about the side effects and herb-drug interaction was found to be inadequate for an effective advising and patient counseling. Pharmacists were more knowledgeable on specific therapeutic indications of herbal products rather than on other areas such as drug-herb interaction or side effects [23,24]. House hold survey on medication published from Oman, overall results suggest an inappropriate use of medicines among the sampled population. Selfmedication with herbal medicines is common entity $[25,26]$.

\section{Conclusion}

Students in clinical years have positive approach towards CAM and their knowledge is adequate in general but they have poor knowledge regarding herbs used as painkiller. Complementary therapy can be a valuable addition to the chronic pain management plan in primary care and students should learn how to apply them in clinical practice with appropriate clinical judgment and awareness of the clinical evidence supporting their use and also showing their limitations.

\section{Study Limitation}

This study is conducted in one medical college so the result regarding medical student's knowledge about CAM cannot be generalized. We need more studies at different medical colleges at different level.

\section{Disclosure Statement}

No competing financial interests exist.

\section{References}

1. WHO (1998) Regulatory situation of herbal medicine. A worldwide review. Geneva.

2. National Center for Complementary and Alternative Medicine (2008). What is complementary and alternative medicine (CAM).

3. Astin JA (1998) Why patients use alternative medicine: results of a national study. JAMA 279: 1548-1553.

4. Hasan MY, Das M, Behjat S (2000) Alternative medicine and the medical profession: views of medical students and general practitioners. East Mediterr Health J 6: 25-33.

5. Goldstein MS, Brown ER, Ballard-Barbash R, Morgenstern H, Bastani R et al. (2005) The use of complementary and alternative medicine among california adults with and without cancer. Evid Based Complement Alternat Med 2: 557-565.

6. Erci B (2007) Attitudes towards holistic complementary and alternative medicine: a sample of healthy people in Turkey. J Clin Nurs 16: 761-768.

7. AlBraik FA, Rutter PM, Brown D (2008) A cross-sectional survey of herbal remedy taking by United Arab Emirate (UAE) citizens in Abu Dhabi. Pharmacoepidemiol Drug Saf 17: 725-732.
8. Xu S, Levine M (2008) Medical residents' and student's attitudes towards herbal medicines: a pilot study. Can J Clin Pharmacol 15: e1-4.

9. Loh KP, Ghorab H, Clarke E, Conroy R, Barlow J (2013) Medical student's knowledge, perceptions, and interest in complementary and alternative medicine. J Altern Complement Med 19: 360-366.

10. Ernst E (2000) Prevalence of use of complementary/alternative medicine: a systematic review. Bull World Health Organ 78: 252-257.

11. Münstedt K, Harren H, von Georgi R, Hackethal A (2011) Complementary and Alternative Medicine: Comparison of Current Knowledge, Attitudes and Interest among German Medical Students and Doctors. Evid Based Complement Alternat Med 2011: 790951.

12. Yeo AS, Yeo JC, Yeo C, Lee CH, Lim LF, et al. (2005) Perceptions of complementary and alternative medicine amongst medical students in Singapore--a survey. Acupunct Med 23: 19-26.

13. Greiner KA, Murray JL, Kallail KJ (2000) Medical student interest in alternative medicine. J Altern Complement Med 6: 231-234.

14. Yildirim Y, Parlar S, Eyigor S, Sertoz OO, Eyigor C, et al. (2010) An analysis of nursing and medical student's attitudes towards and knowledge of complementary and alternative medicine (CAM). J Clin Nurs 19: 1157-1166.

15. Perlman A, Stagnaro-Green A (2010) Developing a complementary, alternative, and integrative medicine course: one medical school's experience. J Altern Complement Med 16: 601-605.

16. Desylvia D, Stuber M, Fung CC, Bazargan-Hejazi S, Cooper E (2011) The knowledge, attitudes and usage of complementary and alternative medicine of medical students. Evid Based Complement Alternat Med 2011: 728902 .

17. Chaterji R, Tractenberg RE, Amri H, Lumpkin M, Amorosi SB, et al. (2007) A large-sample survey of first- and second-year medical student attitudes toward complementary and alternative medicine in the curriculum and in practice. Altern Ther Health Med 13: 30-35.

18. Frenkel M, Frye A, Heliker D, Finkle T, Yzaguirre D, et al. (2007) Lessons learned from complementary and integrative medicine curriculum change in a medical school. Med Educ 41: 205-213.

19. Kashif M, Hussain M, Hussain RK, Saba M, Sana M, et al (2007) Complementary and Alternative Medicine: Perceptions of Medical Students from Pakistan. Med Educ 12:11.

20. Greenfield SM, Brown R, Dawlatly SL, Reynolds JA, Roberts S, et al. (2006) Gender differences among medical students in attitudes to learning about complementary and alternative medicine. Complement Ther Med 14: 207-212.

21. Gaster B, Unterborn JN, Scott RB, Schneeweiss R (2007) What should students learn about complementary and alternative medicine? Acad Med 82: 934-938.

22. Kolkman E, Visser A, Vink A, Dekkers W (2011) CAM-education in the medical curriculum: Attitude towards and knowledge of CAM among Dutch medical students. Eur J Integr Med 3: 17-22.

23. Adisa R, Fakeye T (2006) Assessment of the knowledge of Community Pharmacists regarding common phyto pharmaceuticals sold in South Western Nigeria. Trop J Pharm Res 5(2): 619-625.

24. Duraz AY, Khan SA (2011) Knowledge, attitudes and awareness of community pharmacists towards the use of herbal medicines in muscat region. Oman Med J 26: 451-453.

25. Abdo-Rabbo A, Al-Ansari M, Gunn BC, Suleiman BJ (2009) The use of medicines in oman: public knowledge, attitudes and practices. Sultan Qaboos Univ Med J 9: 124-131.

26. Household Survey on Medicine Use in Oman (2009) Report of survey conducted in 2009 Directorate of Rational Use of Medicines Ministry of Health Muscat, Sultanate of Oman. Oman. 